\title{
Analysis on the Spinning Process and Properties of Tencel Yarn
}

\author{
Ya Wang1*, Dudi Gong2 ${ }^{2}$, Yan Bai', Yunqi Zhai1 \\ ${ }^{1}$ Fashion College, Shanghai University of Engineering Science, Shanghai, China \\ ${ }^{2}$ Shanghai Car Carpet Plant Co., Ltd., Shanghai, China \\ Email: Mrwangya@163.com
}

Received 4 January 2015; accepted 19 January 2015; published 22 January 2015

Copyright (C) 2015 by authors and Scientific Research Publishing Inc.

This work is licensed under the Creative Commons Attribution International License (CC BY). http://creativecommons.org/licenses/by/4.0/

(c) (i) Open Access

\begin{abstract}
Tencel fiber, as a new type of green environmental protection fiber, is drawing attention from the society and people's favorite. In paper, the spinning process and properties of tencel yarn were studied. Also traditional cotton yarn was tested and compared to understand tencel better as they are now both widely used in apparel. Compared with cotton yarn of the same count, the weight CV of tencel quality is lower, while the twist CV is higher; breaking elongation of tencel yarn is larger, while CV of breaking elongation of tencel yarn is slightly higher; unevenness of tencel spinning yarn is lower.
\end{abstract}

Keywords

Tencel, Spinning, Yarn

\section{Introduction}

Tencel fiber is a kind of regenerated cellulose fiber produced in a way called "solvent spinning method", the production mainly uses coniferous wood pulp as raw materials. Tencel fiber has the advantages of both natural fiber and synthetic fiber. Such as cellulose fiber, tencel fiber has good hygroscopicity, permeability and performance, its wearing comfort is much better than polyester, and its feel, gloss, drape are all good. The strength of tencel fiber is higher than that of cotton fiber and viscose fiber; it also has advantages such as warm and soft and comfortable; in addition, tencel has good performance and dimensional stability; it can be blended with other natural fiber and synthetic fiber [1]. The source ingredients of tencel fiber mainly come from green cellulose fiber in nature, chemical solvent used in production can be recycled, so it won't cause any damage to human and the environment. After using, tencel fiber can be decomposed completely in soil, which can greatly reduce the

${ }^{*}$ Corresponding author.

How to cite this paper: Wang, Y., Gong, D.D., Bai, Y. and Zhai, Y.Q. (2015) Analysis on the Spinning Process and Properties of Tencel Yarn. Journal of Minerals and Materials Characterization and Engineering, 3, 41-47.

http://dx.doi.org/10.4236/immce.2015.31006 
environmental destruction, therefore, tencel fiber is also known as "green fiber". Along with the people's gradually increasing attention on environmental protection concept, social demands development towards the direction of environmental protection, spinning of green textiles will become a major trend. Tencel fiber, as a kind of biodegradable fiber, will become the mainstream in the future [2].

\subsection{The Development Status at Home and Abroad}

As a new kind of cellulose fiber, tencel fiber has been published for many years. It's now popular in United States, Japan and other countries mainly for the production of high fashion. Kaoerzi company had started researching cellulose fiber production with NM-MO solvent method since 1978. In 1981, the company used amine oxide as a new solvent to spin; the experiment showed that the spinning method is feasible. In 1983, the company set up experimental factory; in 1987, the continuity of large scale plant was established [3]. In 1989, it's named tencel fiber after recognized by the International Bureau of Artificial and Synthetic Fiber Standards, then American factories began commercial production of tencel and its production capacity had reached 55 millions kilograms. The tencel plant in Crimsby put into production in the beginning of 1997, and its annual production capacity had reached 42,000,000 kilograms. In 1999, output of tencel fiber in Kaoerzi company reached 8,180,000 tons; the output of Japan had reached 20,000 tons - 30,000 tons; in 2000, Kaoerzi company established an tencel fiber factory with annual output of 5,000,000 kilograms in Asia. Tencel products can be decomposed, solvent of which is non-toxic, it also has high recovery rate. So it is regarded as the third generation of regenerated cellulose fiber. Because of its unique properties, it had been applied into a variety of goods in many fields. The whole Asia has also appeared upsurge of tencel development [4]. After promotion and using of new tencel fiber materials, the bottleneck of dyeing obtained effective breakthrough especially in Taiwan. Exhibition held in New York and Milan displayed 300 kinds of tencel fabric samples and 200 pieces of clothing. Tencel products had been in Japanese market for many years, new tencel products were developed in Japan every year. Japan is currently the largest developers of tencel textiles, lots of men products in department stores were tencel goods. It can be said that tencel fiber goods in Japan entered a new stage. Textile software and hardware for tencel, especially the commercialization of tencel commodity, were also under development in Japan. This had helped Japan to maintain a leading position in the manufacturing of tencel fiber. In 2000, the British tencel fiber output reached 6,140,000 tons [5]. China began mass production of tencel fiber and sold related products in 1993. In recent years, the textile and clothing industry have turned their attention to tencel fiber; although the textile and apparel market is not prosperous, the products of tencel material are very popular and have created "tencel miracle" in textile market [6]. Tencel fiber with its incomparable superiority is in rapid development in international and domestic market.

\subsection{Spinning Process}

Tencel fiber can be spinned in cotton spinning system, wool processing system and many other systems, and the technological process of spinning is short. Tencel fiber with good structure and good physical mechanical properties determines its processing has the following characteristics: good spinnability of tencel fiber, excellent yarn physical property. Tencel fiber can spin into yarn with high strength, low unevenness, smooth appearance and perfect quality [7].

Technological process is showing in Diagram 1, Disc Plucker $\rightarrow$ Mixed Opener $\rightarrow$ Double Hopper Feeder $\rightarrow$ Single Beater Scutcher $\rightarrow$ Carding Machine $\rightarrow$ Drawing $\rightarrow$ Machine $\rightarrow$ Roving Machine $\rightarrow$ Spinning Machine $\rightarrow$ Automatic Winder [8] [9].

\subsubsection{Opening}

Tencel fiber has length uniformity, and doesn't have any impurities. It's easy opening and won't produce any neps. So its configuration of blowing-carding unit speed and the space are similar with spinning pure polyester yarn. It should be adopted that "tap and drop little, feed little and frequently, open sufficiently" according to its characteristics, so unit of short flow blowing-carding is used. It should be appropriate to reduce the speed of beater and increase the ratio between the inclined curtain and brad curtain in order to reduce fiber damage and improve the opening degree [10].

\subsubsection{Carding}

Carding process is mainly combing the opening fasciculate and bulk fiber to change the fiber bundles or block 


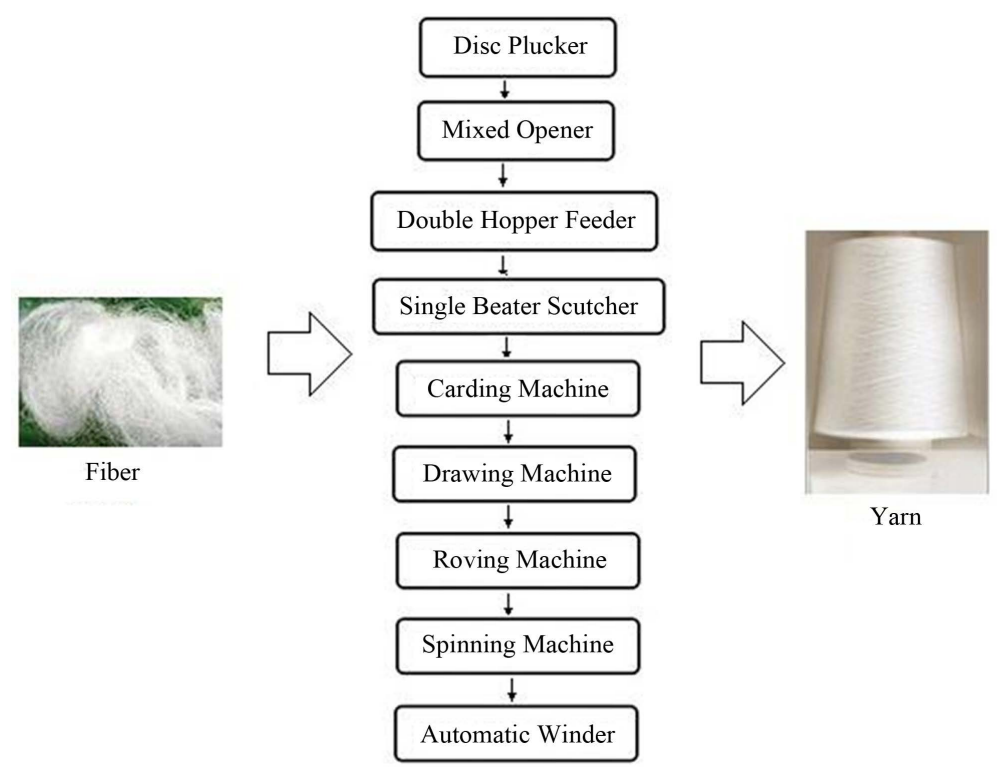

\section{Diagram 1. Technological process.}

into a single state. When combing, not only fiber damage should be reduced to enable it to obtain a smooth transfer, but also fiber winding flower should be avoided from rubbing into neps. In order to spin yarn of high quality, it should be used of the process principle that "lighter weight, low speed" in order to improve cotton web quality; speed of licker-in, cylinder and cover plate should be reduced, spacing between the cover and cylinder should be appropriately amplified and the spacing between cotton feed plate and taker-in gauge should also be appropriately amplified in order to reduce the card sliver rate and improve the yarn evenness; each roller pressure of cotton net out from doffer to circle should be mastered smaller to prevent the card sliver too closely and not conducive to the follow-up process processing [11]. In the production process, if the quantity and speed are not controlled well, cotton net will therefore hole. At the base of slow speed, light quantitate, the tension teeth should be adjusted and the tour should be strengthened in order to improve and enhance the quality of the cotton net. Tencel fiber with larger fiber volume quality is smooth and fluffy, its moisture regain rate is high but its cohesion is not good, so the carding should choose the new chemical fiber spinning clothing in order to reduce yarn neps and improve cotton web quality [12].

\subsubsection{Drawing}

Pure spinning adopts two combining, clockwise drafting. Drawing quantitate should be mastered smaller and roller gauge should be appropriately amplified in order to achieve the purpose of improving evenness. Fiber got into the head combining is mainly front hook, therefore, smaller draft ratio and larger back zone draft multiple should be adopted of the head combining to make hooked fiber straight. Machine speed of Head combining should be reduced in order to reduce the fiber winding roller and rubber; second drawing is mainly in order to make the fiber straight and to make the weight unevenness reduced to a certain extent. Draft configuration should be focused on the front zone to improve straight effect the back hook [11].

\subsubsection{Roving}

Roving twist of tencel fiber should be lower than that of cotton; twist value should be appropriately increased at the base that the spinning hard head will not appear; and roving tension should be controlled. It should be used of the four roller double short apron draft, small tension, large spacing, and the appropriate back zone drafting multiple to reach a stable drafting force, to prevent accidental drafting, to reduce the details and to improve the evenness [10].

\subsubsection{Spinning}

In order to guarantee yarn quality, spinning process should be optimized: According to the characteristics of tencel fiber, drafting force should be reduced; roller pressure and posterior spacing should be increased. What's 
more, centralized drafting should be used in spinning process; at the same time, ring and traveller should be used reasonable in order to reduce yarn hairiness. Suitable hardness roller (the same species yarn with the same model, the same diameter, the same surface treatment method and the same use cycle) should be selected to reduce evenness CV value [10].

\section{Experiments and Analysis}

\subsection{Source Material}

Source material of tencel yarn and cotton yarn is shown in Table 1.

\begin{tabular}{cc} 
Table 1. Source material of tencel yarn and cotton yarn. \\
\hline Material & Source \\
\hline Tencel yarn $40^{\mathrm{s}}, 60^{\mathrm{s}}, 80^{\mathrm{s}}$ & Potow Jinglun Textile Co., Ltd. \\
Cotton yarn $40^{\mathrm{s}}, 60^{\mathrm{s}}, 80^{\mathrm{s}}$ & Yue Da Textile Co., Ltd. \\
\hline
\end{tabular}

\subsection{Analysis of Properties of Tencel Yarn and Cotton Yarn}

\subsubsection{Basic Indexes}

1) YG086C type yarn length measuring instrument, electronic balance, Y802L eight baskets oven thermostat were applied into testing according to GB/T 4743-2009 [13].

The relationship of weight deviation and its CV between tencel yarn and cotton yarn are shown in Figure 1 and Figure 2.

2) Y331A type yarn twist machine was applied into testing according to GB/T 2543.2-2001 [14].

The relationship yarn twist and its CV between cotton yarn and tencel yarn are shown in Figure 3 and Figure 4.

Analysis of Diagrams 1, 2, 3, 4:

a) There is no significant relation of weight deviation between yarn and tencel yarn; compared with cotton yarn of the same count, the weight $\mathrm{CV}$ of tencel is lower than that of cotton quality (the lower the CV value is, the more stable the yarn quality is).

b) At the circumstance that yarn twist values of tencel yarn and cotton yarn are similar, compared with yarn of the same count, the twist CV of tencel yarn is higher than that of cotton yarn.

c) In the twisting process, due to the influence of various factors, the yarn twist unevenness will appear. The yarn twist unevenness will not only affect the appearance of yarn and fabric but also their quality, it will cause the increase of yarn faults, and then result in the decrease of production efficiency [15].

\subsubsection{Tensile Properties}

PC/YG061F type electronic single yarn strength tester was applied into testing according to GB/T 3916-2013 [16].

The relationship breaking strength and its CV between cotton yarn and tencel yarn are shown in Figure 5 and Figure 6.

The relationship of yarn and its average breaking elongation and CV are shown in Figure 7 and Figure 8.

Analysis of Diagrams 5, 6, 7, 8:

Compared with yarn of the same count, breaking strength of tencel yarn is higher than cotton yarn except it's around $60 \mathrm{~s}$; Breaking strength CV of tencel yarn is higher than cotton yarn except it's around $80 \mathrm{~s}$.

2) Compared with yarn of the same count, breaking elongation of tencel yarn is higher; CV of breaking elongation of tencel yarn is slightly higher than that of cotton yarn, and it goes nearer of CV of breaking elongation between tencel yarn and cotton yarn.

\subsubsection{Frequent Defects}

YG172 type yarn hairness test machine was applied to test yarn hairness according to FZ/T 01086-2000 [17]; YG381 type shake the board machine was applied into testing according to GB/T 9996.2-2008 [18].

Frequent defects of tencel yarn in different count are shown in Table 2.

Frequent defects of cotton yarn in different count are shown in Table 3. 


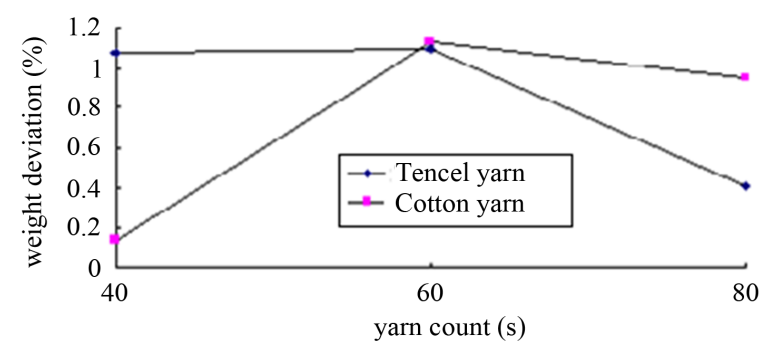

Figure 1. Tencel yarn and cotton yarn weight deviation.

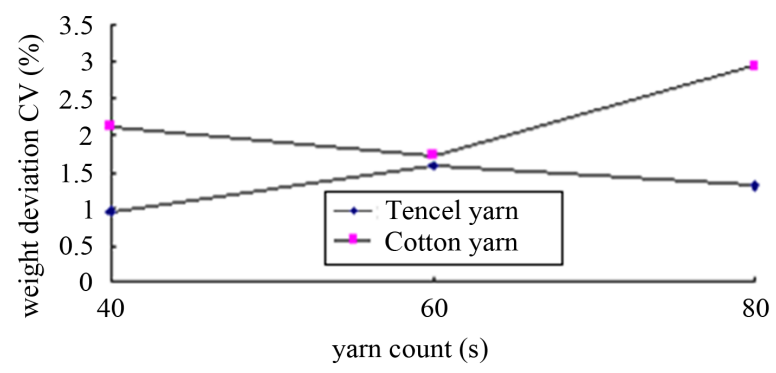

Figure 2. Tencel yarn and cotton yarn weight CV.

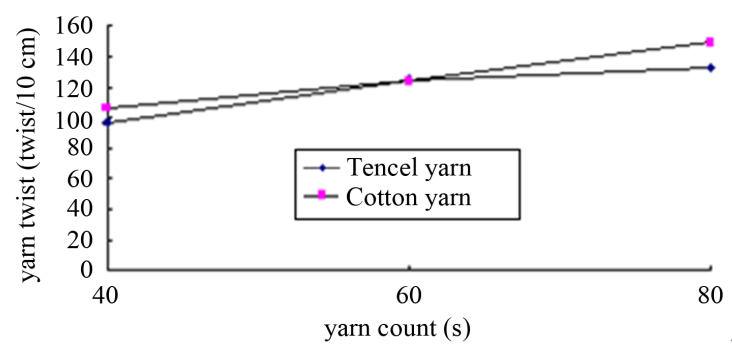

Figure 3. Tencel yarn and cotton yarn twist.

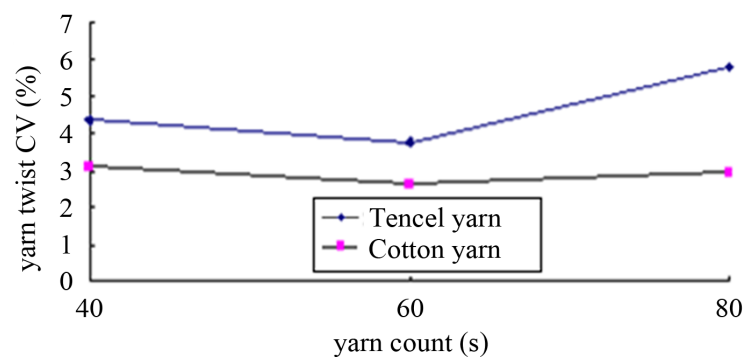

Figure 4. Tencel yarn and cotton yarn twist CV.

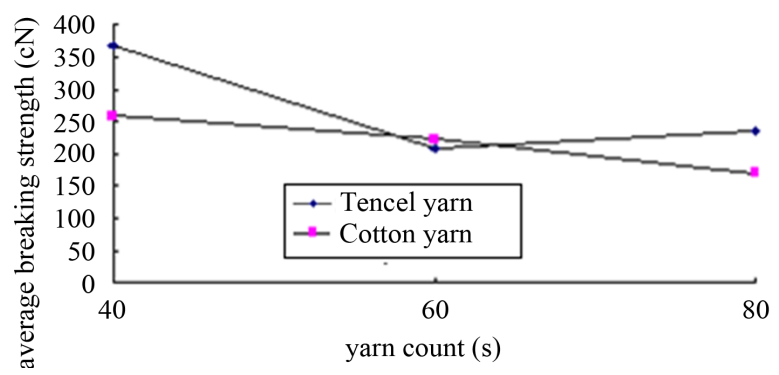

Figure 5. The relationship of average breaking strength between tencel yarn and cotton yarn. 


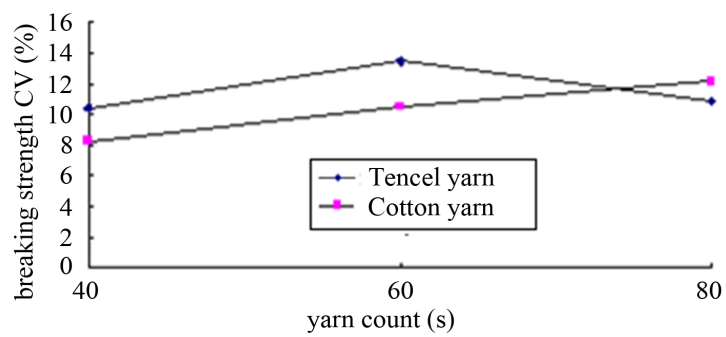

Figure 6. Breaking strength CV of tencel yarn and cotton yarn.

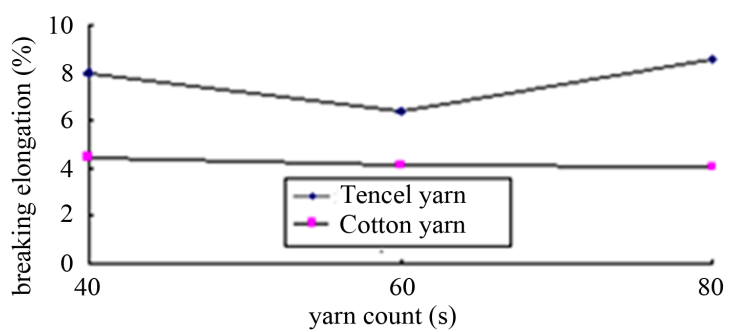

Figure 7. Tencel yarn and cotton yarn breaking elongation.

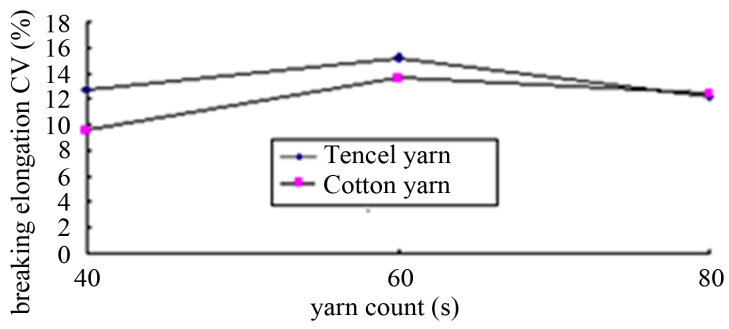

Figure 8. Tencel yarn and cotton yarn CV of breaking elongation.

Table 2. Frequent defects of tencel yarn.

\begin{tabular}{cccc}
\hline Yarn specifications & $40^{\mathrm{s}}$ & $60^{\mathrm{s}}$ & $80^{\mathrm{s}}$ \\
\hline Hairiness value & 3.72 & 4.69 & 2.8 \\
Evenness CV(\%) & 11.54 & 13.86 & 12.2 \\
The $-50 \%$ km details & 0 & 2 & 2 \\
The $+50 \%$ km details & 9 & 45 & 11 \\
The $+200 \%$ km details & 33 & 112 & 37 \\
\hline
\end{tabular}

Table 3. Frequent defects of cotton spinning.

\begin{tabular}{cccc}
\hline Yarn specifications & JC40 $^{\text {s }}$ & JC60 $^{\text {s }}$ & JC80 $^{\text {s }}$ \\
Hairiness value & 4.72 & 3.85 & 3.37 \\
Evenness CV(\%) & 13 & 14.21 & 15.29 \\
The $-50 \%$ km details & 5 & 17 & 48 \\
The $+50 \%$ km details & 21 & 66 & 125 \\
The $+200 \%$ km details & 32 & 190 & 313 \\
\hline
\end{tabular}


Analysis of Table 2 and Table 3:

1) Surface of tencel is relatively smooth, it has high initial modulus and strong rigidity. The fiber is not easy to be attached on the surface of wool or yarn, which will result in hairness [19].

2) Compared with yarn of the same number, unevenness of tencel spinning yarn is lower and its appearance is smoother, this is because that tencel fiber is clean without impurities and short fiber and has good physical and mechanical properties.

\section{Conclusion}

Tencel fiber with high strength can be spun into yarn that is very fine but with very high strength. Nature cellulose fiber amount is limited for human to use, while the chemical fiber helps people solve the problem in a certain extent, but the chemical fiber pollution in the environment is serious, and it also plagued us that it's difficult to solve the problem in a short time. Significant environmental performance of tencel fiber will come out on top in future textile market.

\section{References}

[1] Wen, H.Y. and Yang, X.J. (2007) The Spinning Process of Tencel Pure and Blended Yarn. Progress in Textile Science and Technology, 1, 44-45.

[2] Xu, Y.J. and Wang, J.H. (2006) A New Generation of Cellulose Fibers-Tencel and Its Analysis. China Fiber Inspection, 1, 43-45.

[3] (1989) New Viscose Fiber “Tencel”. Modern Chemical Industry, 25-27.

[4] (1999) Taiwan Textile Industry Development Fever Caused by Tencel. Foreign Textile Technology, 4, 45-46.

[5] Wang, M. (2003) Application and Development of Tencel Fiber. Foreign Textile Technology, 4, 4-5.

[6] Li, X.G., Zhang, B. and Xue, R. (2004) Production and Development of Tencel Yarn. Beijing Textile, 25, 25-30.

[7] Wang, Y.K. and Yang, S.T. (2005) The Structure and Property of Tencel Fiber. China Fiber Inspection, 3, 47-48.

[8] Yang, B.B. and Gong, X.N. (1999) Design of Tencel Spinning Process. Tianjin Textile Science \& Technology, 3, 2628.

[9] Dong, C.J. (2003) Tencel Fiber Spinning Process. Symposium Set of 2003 National Traditional Ring Spinning Technology Progress, 126-132.

[10] Diao, W.L. (2006) Properties of Tencel Fiber and Its Spinning Practice. Progress in Textile Science and Technology, 3 , 70-71.

[11] Zhang, Z.P. and Weng, Y. (2003) The Spinning Process of Tencel Fiber. Shandong Textile Science \& Technology, 5, 24-25.

[12] Tu, Z.X., Fu, B.K. and Zhou, G.Q. (2001) Spinning Practice of Tencel Fiber. Cotton Textile Technology, 29, 45-46.

[13] GB/T 4743 (2009) Textiles_-Yarn from Packages—Determination of Linear Density (Mass per Unit Length) by the Skein Method.

[14] GB/T 2543.2 (2001) Textiles_-Determination of Twist in Yarn Part 2: Untwist-Retwist Method.

[15] Zhang, Y.H. (2012) Analysis of Unevenness of Yarn Twist Influence Factor. Shanghai Textile Science \& Technology, 40, 54-56.

[16] GB/T 3916 (2013) Textiles_-Yarns from Packages—Determination of Single-End Breaking Force and Elongation at Break Using Constant Rate of Extension (CRE) Tester.

[17] FZ/T 01086 (2000) Textiles_-Test Method for Yarn Hairness_-Projection Counting Method.

[18] GB/T 9996.2 (2008) Determination of Appearance Quality of Yarns Made of Cotton or Man-Made Fibers, or Their Blends by Winding on the Black Board-Part 2: Individual Assessment.

[19] Hu, B.Z. and Yan, J. (2010) Hairiness Control Measures of Tencel Yarn. Shanghai Textile Science \& Technology, 38, 45-47. 
Scientific Research Publishing (SCIRP) is one of the largest Open Access journal publishers. It is currently publishing more than 200 open access, online, peer-reviewed journals covering a wide range of academic disciplines. SCIRP serves the worldwide academic communities and contributes to the progress and application of science with its publication.

Other selected journals from SCIRP are listed as below. Submit your manuscript to us via either submit@scirp.org or Online Submission Portal.
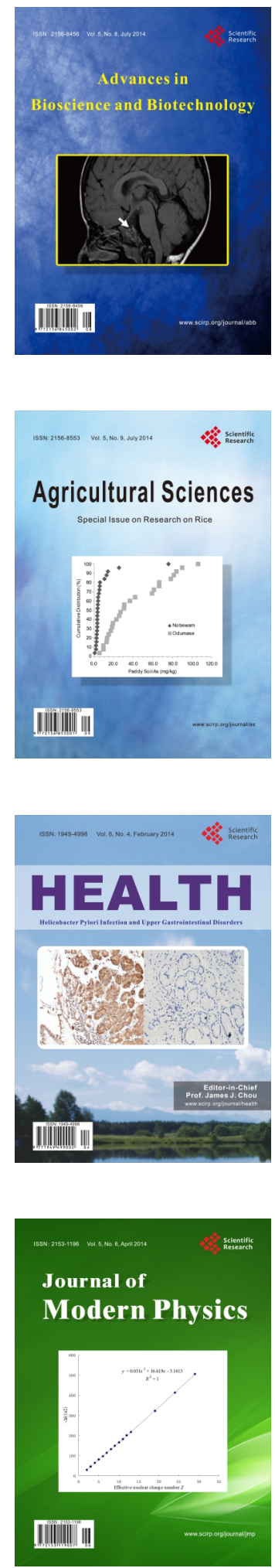
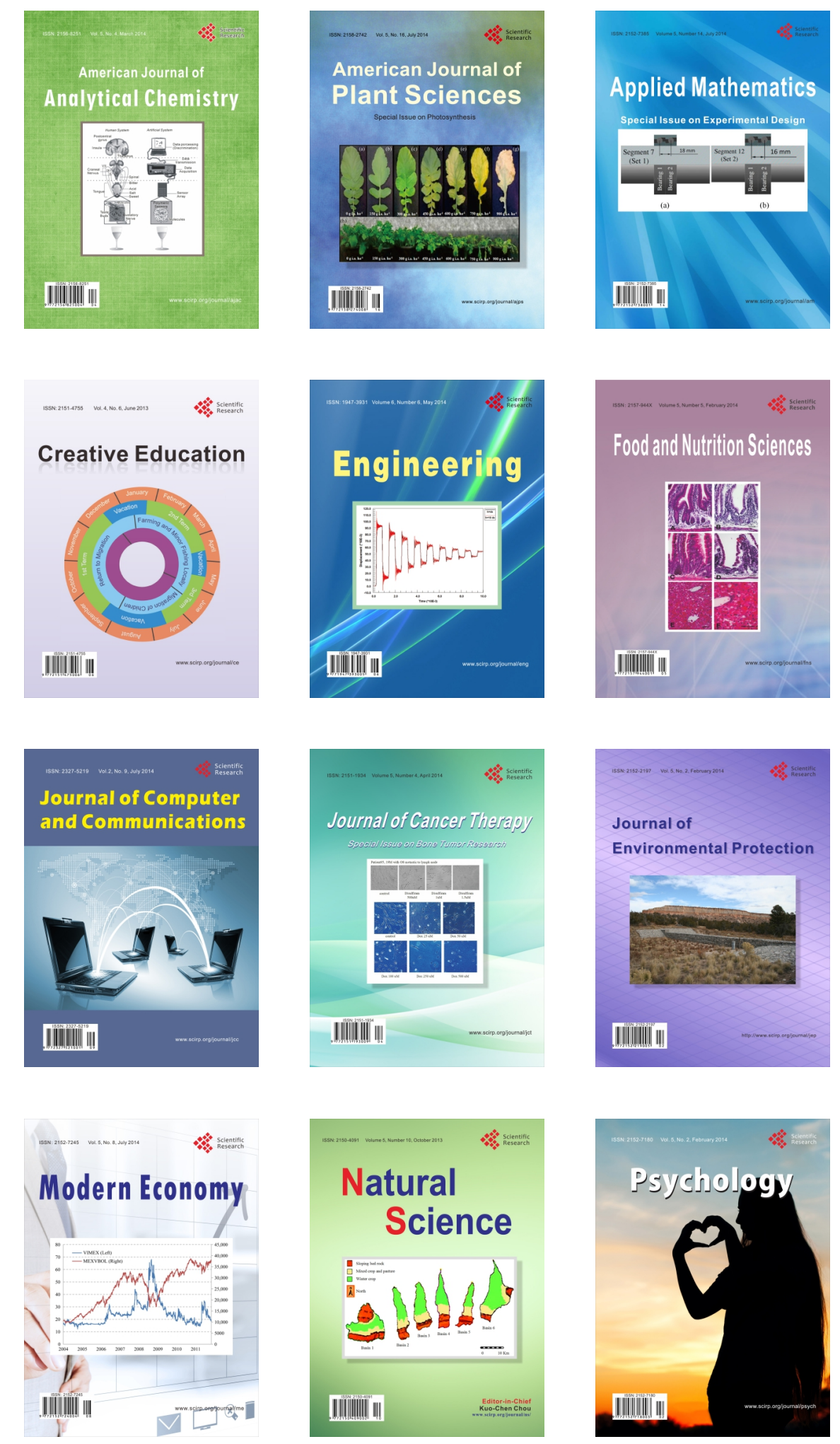